\title{
Role of glial filaments in cells and tumors of glial origin: a review
}

\author{
James T. Rutka, M.D., Ph.D., Masaji Murakami, M.D., Peter B. Dirks, M.D., Sherri Lynn \\ Hubbard, B.Sc., Laurence E. Becker, M.D., Kozo Fukuyama, M.D., Shin Jung, M.D., and Kazuhito \\ Matsuzawa, M.D.
}

Brain Tumor Research Laboratory, Divisions of Neurosurgery and Neuropathology, The Hospital for Sick Children, The University of Toronto, Toronto, Ontario, Canada

In the adult human brain, normal astrocytes constitute nearly $40 \%$ of the total central nervous system (CNS) cell population and may assume a star-shaped configuration resembling epithelial cells insofar as the astrocytes remain intimately associated, through their cytoplasmic extensions, with the basement membrane of the capillary endothelial cells and the basal lamina of the glial limitans externa. Although their exact function remains unknown, in the past, astrocytes were thought to subserve an important supportive role for neurons, providing a favorable ionic environment, modulating extracellular levels of neurotransmitters, and serving as spacers that organize neurons. In immunohistochemical preparations, normal, reactive, and neoplastic astrocytes may be positively identified and distinguished from other CNS cell types by the expression of the astrocyte-specific intermediate filament glial fibrillary acidic protein (GFAP). This GFAP is a 50-kD intracytoplasmic filamentous protein that constitutes a portion of, and is specific for, the cytoskeleton of the astrocyte. This protein has proved to be the most specific marker for cells of astrocytic origin under normal and pathological conditions. Interestingly, with increasing astrocytic malignancy, there is progressive loss of GFAP production. As the human gene for GFAP has now been cloned and sequenced, this review begins with a summary of the molecular biology of GFAP including the proven utility of the GFAP promoter in targeting genes of interest to the CNS in transgenic animals. Based on the data provided the authors argue cogently for an expanded role of GFAP in complex cellular events such as cytoskeletal reorganization, maintenance of myelination, cell adhesion, and signaling pathways. As such, GFAP may not represent a mere mechanical integrator of cellular space, as has been previously thought. Rather, GFAP may provide docking sites for important kinases that recognize key cellular substrates that enable GFAP to form a dynamic continuum with microfilaments, integrin receptors, and the extracellular matrix.

Key Words * glial filament * glial fibrillary acidic protein * cytoskeleton * intermediate filament * phosphorylation * kinase * astrocyte

The astrocyte is a central nervous system (CNS)-specific cell type derived embryologically from a primitive neuroepithelial stem cell within the ependymal zone. This stem cell differentiates into an astrocyte as it migrates radially from the neuroepithelium to reside ultimately in the parenchyma of the brain.[62] In the adult human brain, normal astrocytes constitute nearly $40 \%$ of the total CNS cell population and may assume a star-shaped configuration resembling epithelial cells insofar as the 
astrocytes remain intimately associated, through their cytoplasmic extensions, with the basement membrane of the capillary endothelial cells and the basal lamina of the glial limitans externa. Almost the entire surface of the CNS is covered by a layer of astrocytic processes interposed between the brain parenchyma and the pial membrane. When the extreme convolution of the CNS and the richness of its vascular bed are taken into consideration, the lush extent of this peripheral astrocytic expansion is truly remarkable. Although their exact function remains unknown, astrocytes probably subserve an important supportive role for neurons, providing a favorable ionic environment, modulating extracellular levels of neurotransmitters, and serving as spacers that organize neurons.[45]

\section{BIOLOGICAL FEATURES OF ASTROCYTES}

Astrocyte swelling represents one of the initial reactions of astrocytes to a variety of insults, the most important of which is hypoxia. Following injury to the human CNS, as a result of trauma, disease, genetic disorders, or chemical insults, astrocytes become "reactive" and respond in a stereotypical manner termed astrogliosis.[27] Astrogliosis is characterized by astrocyte proliferation and extensive hypertrophy of the cell body and cytoplasmic processes. The hallmark cytopathological feature of astrogliosis is a marked upregulation of cytoplasmic glial filaments (see following section). Two examples of human diseases in which the process of astrogliosis is particularly intense are multiple sclerosis and leukodystrophy.

The process of astrogliosis has been thoroughly studied in experimental models of cerebral trauma using cryogenic lesions and stab wounds.[67,72,112,113] Evidence exists that the local activation of astrocytes in these models is mediated by cytokines and growth factors including interleukin (IL)-1, IL-6, transforming growth factor-alpha, transforming growth factor-beta1, tumor necrosis factor-alpha, gamma-interferon, and basic fibroblast growth factor.[2,31,32,33,40,53,58,82,119,120]

Interestingly, astrocytes have the highest predisposition to malignant transformation of any CNS cell type. The astrocytoma is the most common brain tumor arising in the CNS, accounting for $65 \%$ of all primary brain tumors. The majority of astrocytomas are histologically malignant neoplasms.

Astrocytomas are also the most common neoplasm among the childhood brain tumors. Although the majority of astrocytomas in children may not be histologically malignant, nonetheless they frequently cause serious morbidity because of their location in vital areas of the brain, such as the brainstem, optic nerves, and pineal region. No direct cause for the development of astrocytomas in either children or adults has been found. Although there is a body of circumstantial evidence linking these tumors to trauma, prior irradiation, viral infections, and environmental and nutritional factors, clear-cut evidence implicating any one of these is lacking.

The malignant astrocytoma is a highly invasive neoplasm infiltrating diffusely into regions of normal brain, rendering total surgical extirpation impossible and effective local radiation therapy difficult. For poorly understood reasons, malignant astrocytomas rarely give rise to systemic metastases.[103] Rather, tumor progression and death are the result of unremitting local disease. Histopathologically, the malignant astrocytoma is a highly anaplastic and heterogeneous tumor. Although the histogenesis of the malignant astrocytoma is not well understood, there are data to indicate that a malignant astrocytoma may either derive from a less malignant precursor astrocytoma[59] or, more commonly, arise de novo from a cytogenetically perturbed normal astrocyte. In immunohistochemical preparations, normal, reactive, and neoplastic astrocytes may be positively identified and distinguished from other CNS cell types by the expression of glial filaments that are supramolecular filamentous networks comprised of 
glial fibrillary acidic protein (GFAP) (Fig. 1).

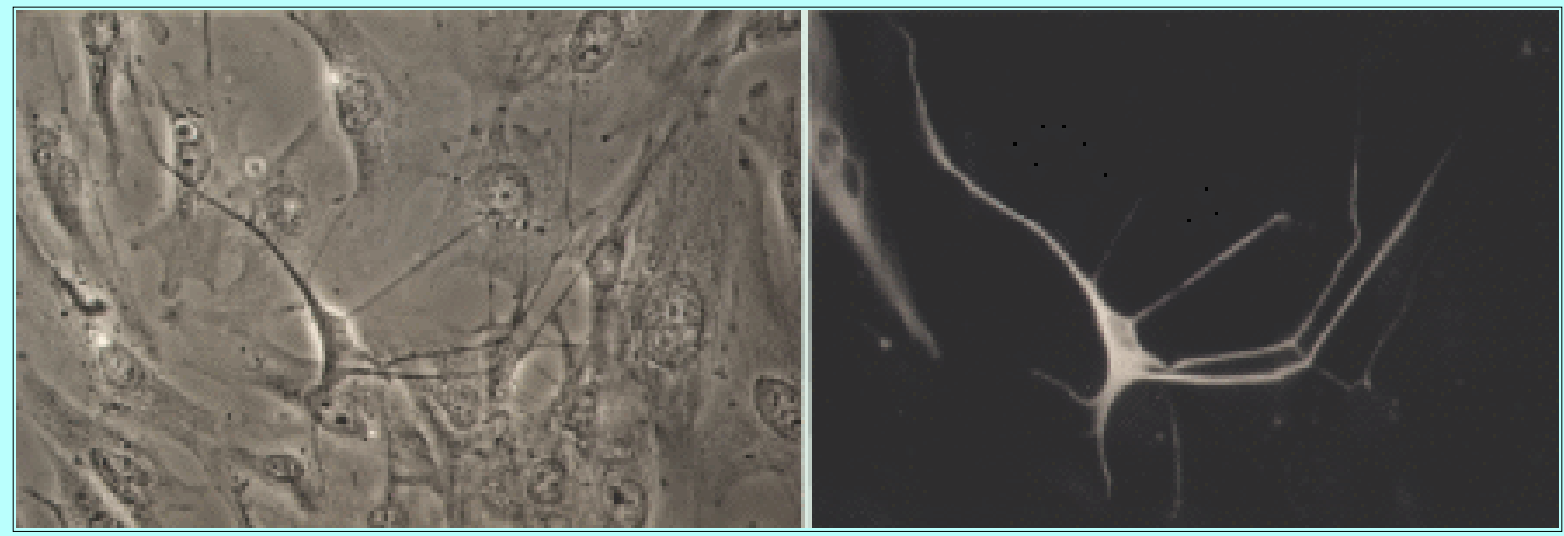

Fig. 1. Photomicrographs showing astrocytes recognized by the anti-GFAP monoclonal antibody. Left: Monolayer of cell types growing in culture from a specimen of normal human brain. Phase-contrast microscopy, original magnification X 250. Right: In this field of heterogeneous cell types, two astrocytes are clearly depicted by the anti-GFAP antibody. Immunofluorescence microscopy, original magnification X 250.

\section{INTERMEDIATE FILAMENTS: CLASSIFICATION AND STRUCTURE}

The cytoskeleton of eukaryotic cells is composed of three major protein networks: 1) the 6-nm-diameter actin microfilaments; 2) the 20-nm-diameter microtubules; and 3) the intermediate filaments (IFs) that range in diameter from 8 to $12 \mathrm{~nm}$, so named because they are intermediate in size between the actin microfilaments and the microtubules. In contrast to the evolutionarily conserved actin and microtubule proteins, IF proteins are highly diverse and exhibit cell type specificity of expression. Intermediate filament gene expression is also tightly coordinated with organ development and tissue differentiation. Accordingly, IFs provide valuable tools with which to study cell determination and differentiation.

On the basis of amino acid sequence homologies and intron positions, IFs can be subdivided into at least six principal types.[34] Keratins are the sole members of the Type I (acidic) and Type II (basic) classes. Vimentin, desmin, GFAP, and peripherin are designated as Type III IF proteins, sharing more than 70\% sequence homology (Fig. 2). The neurofilament proteins are composed of light, medium, and heavy chain proteins and, together with alpha-internexin, are classified as Type IV IFs. Lamin is the only example of a Type V IF. A new IF protein, called nestin, which is clearly a member of the IF superfamily, based on sequence and structure analyses, and which has been localized to neuroepithelial stem cells early in neuroembryogenesis, has been described and classified as a Type VI IF.[61] 


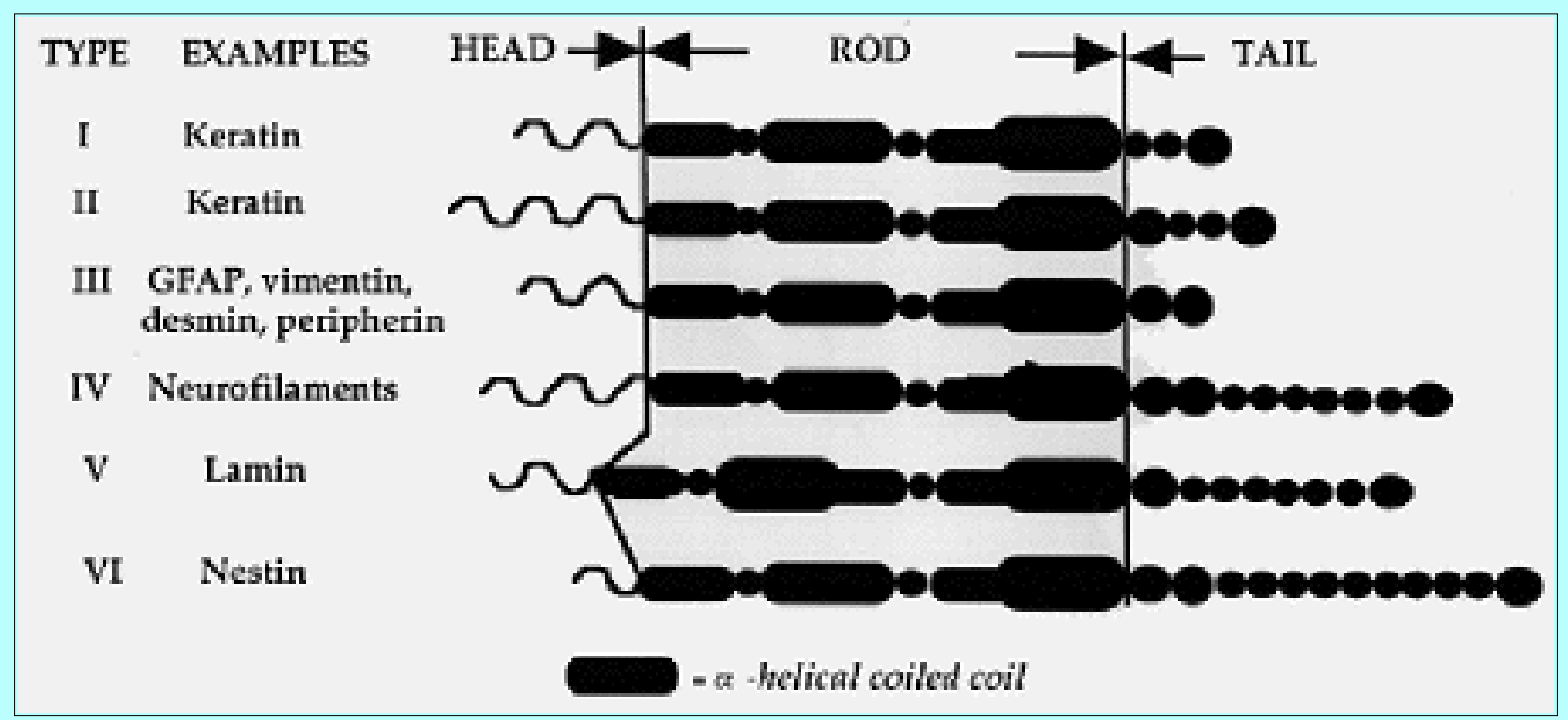

Fig. 2. Classification and structure of the IF family of proteins. On the basis of amino acid sequence homologies, the IFs can be subdivided into six principal types as shown. Whereas the head and tail domains of the IF subtypes vary considerably and provide the basis, in part, for their tissue-specific expression, there is considerable homology within the central rod domain, which is composed of interconnected protein segments forming alpha-helical coils. Glial fibrillary acidic protein is a Type III IF along with vimentin, desmin, and peripherin. In the CNS, neurofilaments provide structural integrity for neuronal axons. Nestin, the newest member of the IF family, is expressed in embryonic stem cells during neuroembryogenesis.

\section{GLIAL FIBRILLARY ACIDIC PROTEIN: A MARKER FOR CELLS AND TUMORS OF GLIAL ORIGIN}

Glial fibrillary acidic protein is a $50-\mathrm{kD}$ intracytoplasmic filamentous protein that constitutes a portion of, and is specific for, the cytoskeleton of the astrocyte. This GFAP shares considerable structural homology with the other IFs in the central alpha-helical or rod domain.[60] In sharp contrast to this highly conserved central rod domain, the $\mathrm{NH}_{2}$ - and $\mathrm{COOH}$-terminal regions of all IFs have distinct amino acid sequences and widely divergent structural features (Fig. 2).[60,83,109] Because of the variability in the $\mathrm{NH}_{2}$-terminal segment among the several classes of IFs, this segment has been presumed to participate in the regulatory functions of these proteins. In the case of GFAP, all four amino acid residues in the $\mathrm{NH}_{2}$-terminal region that undergo phosphorylation are located here (see discussion of phosphorylation in Posttranslational Modifications of GFAP).[47]

First isolated from white matter plaques of patients with longstanding multiple sclerosis,[29] GFAP is the most widely used marker for cells of astrocytic origin under normal and pathological conditions.[20,21] Highly specific polyclonal antibodies to human GFAP have been available since approximately 1975, and application of these antibodies to immunohistochemical studies in the CNS have been extremely helpful in determining brain response to injury and in refining tumor diagnosis.[20,21] That notwithstanding, GFAP immunohistochemistry may lead to variable results depending on the type of antiserum used (polyclonal antisera vs. monoclonal antibodies), shelf life of the primary antiserum used, type of fixative, interval of fixation, and embedding medium selected.[69] McLendon, et al.,[70] and Pegram and colleagues[85] have shown that monoclonal antibodies reacting to different epitopes of GFAP can be combined to enhance the specificity and sensitivity of GFAP immunostains in fixed tissue 
sections.

Interestingly, with increasing astrocytic malignancy, there is progressive loss of GFAP production.[20,21,25,26,28,50] By immunohistochemical analysis, malignant astrocytomas are shown to have fewer tumor cells that stain positively and intensely for GFAP than do less malignant astrocytomas and normal brain specimens.[26,28] For these reasons, GFAP has been considered a reliable marker of differentiation in normal astrocytes and tumors of astrocytic lineage. It is also well accepted, however, that GFAP may be found much less commonly in CNS tumor cells that, although neuroepithelial in origin, are not strictly speaking astrocytic, including the oligodendroglioma, ependymoma, primitive neuroectodermal tumor, and choroid plexus papilloma.[19,56,65,73,77,92,95] In these tumor types, care must be taken to distinguish between GFAP-positive neoplastic cells and entrapped or peritumoral reactive astrocytes, both of which express abundant GFAP.[19,77] Interestingly, GFAP may be expressed in cells outside the CNS, such as nonmyelinating Schwann cells, the epithelium of the lens, the epithelial cells of salivary glands and their neoplasms, and neoplastic cells of mullerian origin.[95]

\section{Molecular Biology of GFAP}

The amino acid sequence of human GFAP has been deduced from the nucleotide sequence of complementary (c)DNA clones encoding this protein. $[9,12,91]$ Mouse and human GFAP genomic genes have also been cloned and sequenced.[3,63,80] There is high homology among rat, mouse, and human GFAP in the coding regions of the gene, but less so in the 3' untranslated region. As such, GFAP shows 90 to $95 \%$ homology between species.[10] Bongcam-Rudloff, et al.,[9] have used Southern blot hybridization of somatic cell hybrids and in situ hybridization to assign the chromosomal location of the human GFAP gene to chromosome 17 (17q21). Mapping studies indicate that GFAP is part of a large syntenic gene cluster including at least 22 genes located on chromosome 17[57] (Fig. 3). 


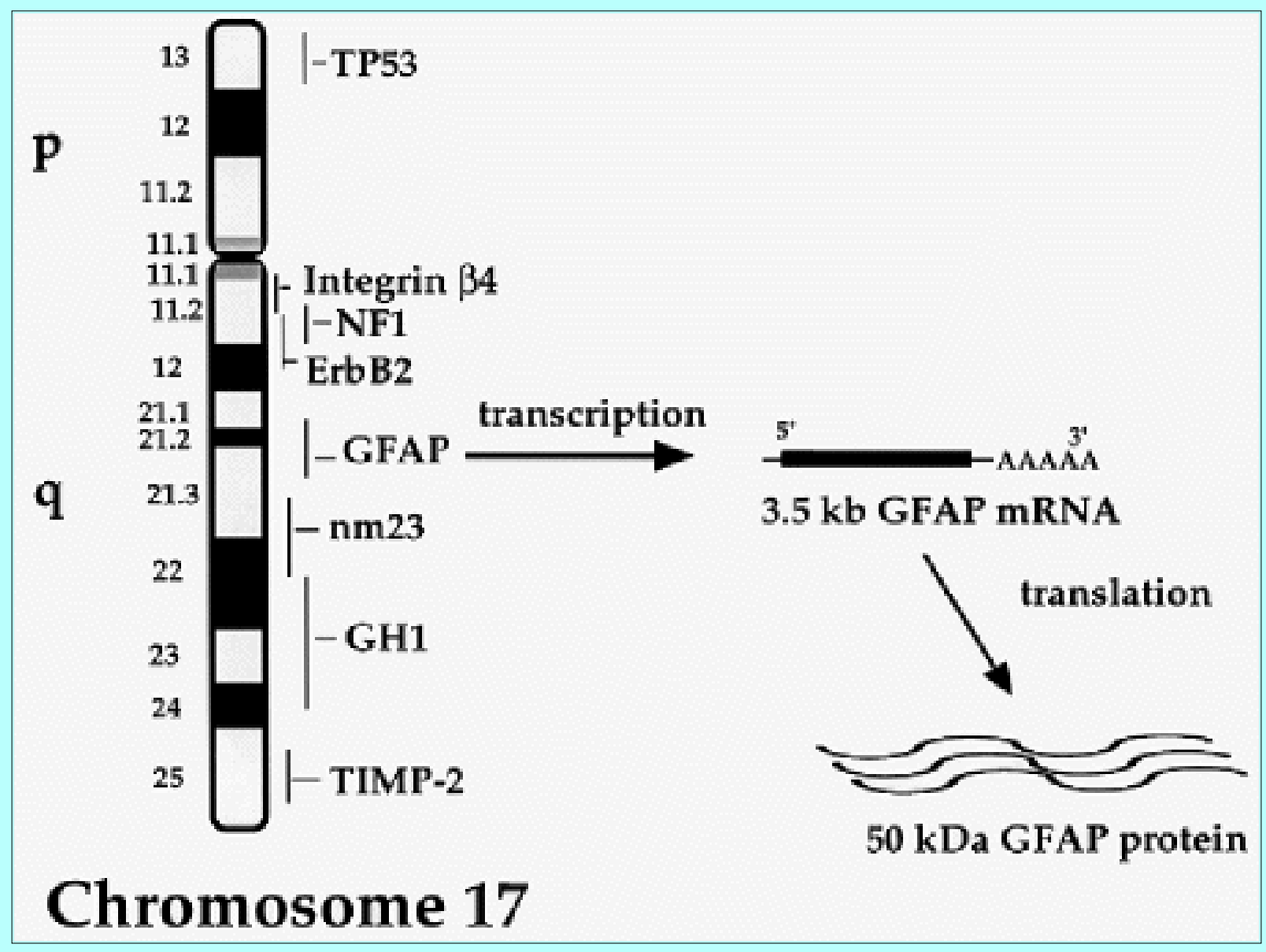

Fig. 3. Map of chromosome 17. The gene for GFAP has been localized to 17q21. Several other genes that have been implicated in the process of glial oncogenesis are also shown, including the genes for $\mathrm{p} 53$ on the short arm of chromosome 17 and neurofibromatosis Type $I(N F-1)$, tissue inhibitor of metalloproteinase (TIMP)-2, and integrin b4. The $n m 23$ is a gene implicated in tumor metastasis. Growth hormone $1(\mathrm{GH} 1)$ is localized to $17 \mathrm{q} 22$ to 17q24. Following gene transcription, a 3.5-kb GFAP mRNA is produced. Translation of this message leads ultimately to the formation of a $50-\mathrm{kD}$ protein that is readily detected in cells and tumors of glial origin by using immunochemical techniques.

Transcriptional Regulation of the GFAP Gene. Protein-encoding mammalian genes frequently contain a basal promoter region with DNA sequences that guide the transcription of the gene by assembling RNA polymerase II and other general transcription factors. In most mammalian genes, the repeated DNA nucleotide sequence of thymidine-adenosine-thymidine-adenosine (or "TATA" sequence) is found 29 to 33 bp upstream of the RNA start site. This TATA box binds general transcription factor IID, which is essential for the transcription of the gene from DNA to messenger (m)RNA. Nakatani and associates[80] showed that GFAP has a basal promoter sequence with the "TAT" motif 29 bp from the RNA start site (Fig. 4). 


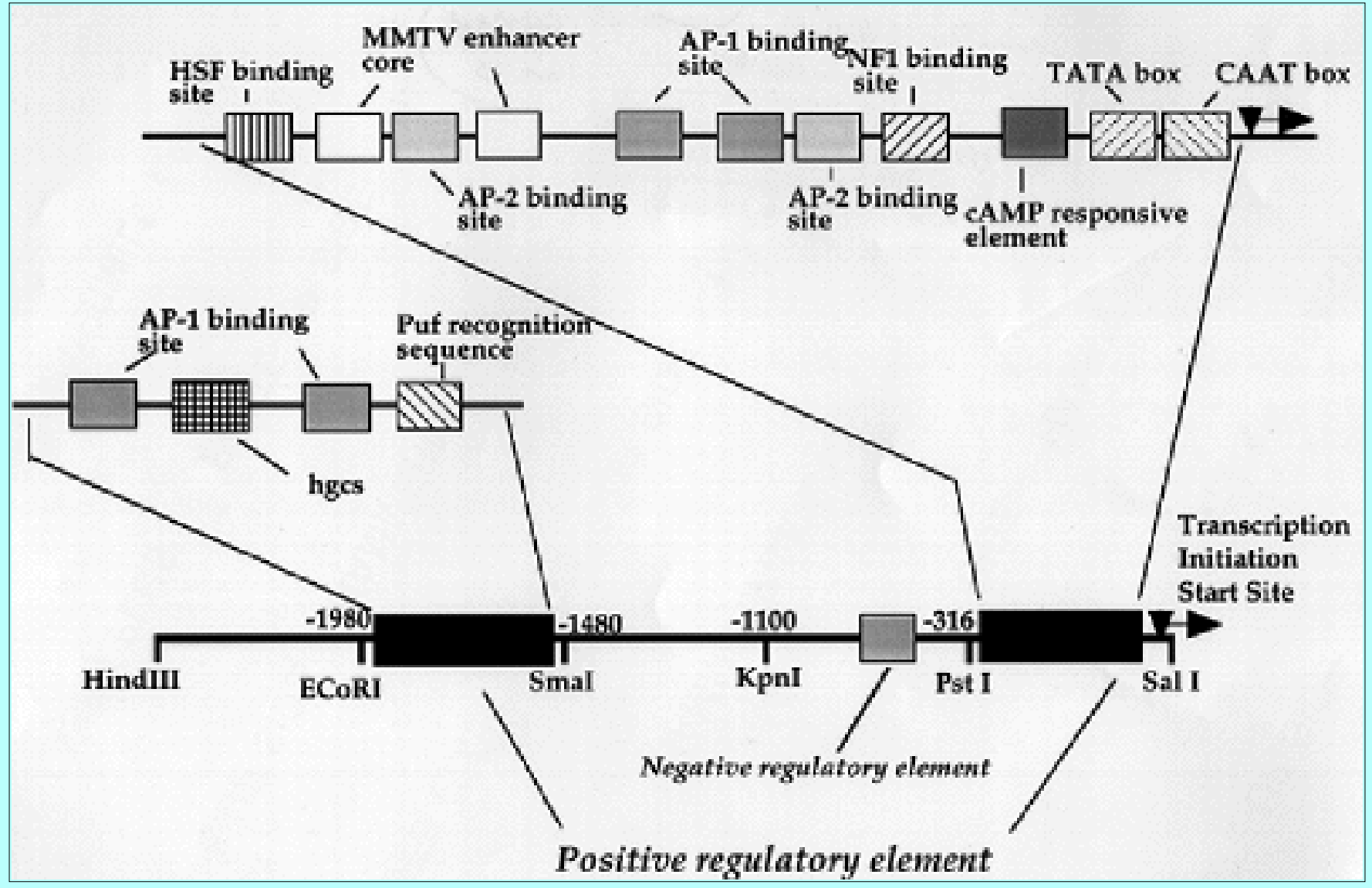

Fig. 4. Model of the GFAP promoter including the region $2 \mathrm{~kb}$ upstream from the initiation start site. In addition to transcriptional regulation by basal promoter sequences such as "TATA" and "CAAT," expression of the GFAP gene is controlled, in part, by positive regulatory elements between -250 and $-80 \mathrm{bp}$ and between -1980 and $-1500 \mathrm{bp}$, and a negative regulatory region at -650 to $-360 \mathrm{bp}$. Within the positive regulatory region, the human GFAP promoter contains transcription factor binding sites for the cAMP responsive element binding protein, NF-1, AP-1, and AP-2 transcription factors. These transcription factors are among the first proteins induced by many stimuli and mediate some of the changes in gene regulation induced by hormones, growth factors, and antigens. The positive regulatory region between -1980 and -1500 bp also contains DNA sequence information that confers glial cell-specific expression of GFAP. This sequence has been termed the human GFAP consensus sequence (hgcs).

In addition to transcriptional regulation by basal promoter sequences such as TATA, the pattern of expression for a gene is also controlled in part by other DNA sequences that activate or inhibit transcription. Sequences that activate gene transcription are called "enhancers," whereas those that inhibit gene transcription are called "silencers." These sequences are typically found within 1 to $2 \mathrm{~kb}$ upstream of the RNA start site, but may be located further upstream or downstream depending on the tertiary or quaternary structure of the gene. In general, gene enhancers or silencers achieve their effects by binding proteins that interact directly with the basal transcriptional machinery or indirectly through intermediary proteins. The results from a number of laboratories now show that gene enhancer or positive regulatory regions of the GFAP gene exist between -250 and $-80 \mathrm{bp}$ and between -1980 and $-1500 \mathrm{bp},[10]$ and a gene silencer or negative regulatory region is found at -650 to $-360 \mathrm{bp}$ (Fig. 4). Within its positive regulatory region, the human GFAP promoter contains transcription factor binding sites for the cyclic adenosine monophosphate (cAMP) responsive element-binding protein, Sp-1, NF-1, AP-1, and AP-2 
transcription factors. [4] These transcription factors are among the first proteins induced by many stimuli and mediate some of the changes in gene regulation induced by hormones, growth factors, and antigens. As one example, the ILs, which are released during brain inflammatory responses, lead to increased levels of $c$-jun and $c$-fos. These early response genes have been shown to bind to the AP-1 binding site on the GFAP promoter indicating that one of the effects of cytokine expression may be increased GFAP transcription.[58]

The promoter region of the GFAP gene also contains DNA sequence information that confers glial cell-associated expression to cells of the CNS, namely the astrocytes. As for the sequence of the GFAP promoter that controls glial cell-associated expression, there has been some debate among different laboratories. However, a consensus sequence for glial cell-specific expression has been located in the positive regulatory region of the human GFAP promoter and has been termed the human GFAP consensus sequence, or "hgcs."[4,66] At the present time, a yet-to-be-determined transactivating protein(s) binds this sequence and enhances GFAP transcription. Once identified, this protein, which specifically binds to the GFAP promoter and enhances glial cell-specific expression, may be used with the GFAP promoter that is linked to other genes of interest in neurobiology or neurooncology to express them specifically in astrocytes in culture or in transgenic animals (see following subsection). The information obtained from such studies could conceivably lead to interventions in brain disorders during neural development, brain injury, and glial tumorigenesis.

Glial Fibrillary Protein-Transgenic Mouse Studies. Attempts to elucidate the function of given proteins have been enhanced significantly since the development of transgenic mouse technology, in which a gene encoding the protein of interest can be microinjected into a developing mouse embryo (Fig. 5). Once born, the mouse displays the phenotype of the protein, which may be expressed either ectopically or in excess. The first reported transgenic study using the GFAP gene was reported by Mucke, et al.[76] In that report and in several others that followed,[11] the promoter region of the GFAP gene was found to direct the activity of a reporter gene in cells of the CNS with little, if any, expression in other organs. As one example, Campbell, et al.,[14] used a GFAP-transgene cassette to express IL-6 in mouse brain astrocytes. The transgenic mouse offspring were found to have stunted growth, ataxia, and seizures. Neuropathological examination of these animals revealed loss of, and damage to, neurons and dendrites, marked astrogliosis, and some neovascularization.[14] The induction of acute-phase proteins by IL-6 was thought to be responsible for the immunological responses observed in the CNS. In another study, Toggas and colleagues[114] created transgenic mice from a construct in which the human immunodeficiency virus- 1 coat was attached to the GFAP promoter. In these mice, considerable neuronal damage was found on neuropathological examination.[114] Finally, a study by Galou, et al.,[35] showed that a 2-kb fragment of the 5' flanking region of the murine GFAP gene linked to a beta-galactosidase reporter gene was activated following a stab wound to the brain in transgenic mice. These transgenic lines may thus provide a useful tool to study certain aspects of reactive astrocytosis. In all the studies just described, the ability of GFAP DNA regulatory sequences to target expression of transgenes to cells of glial origin opens exciting opportunities to influence the behavior of astrocytes or to target tumors of astrocytic origin. 


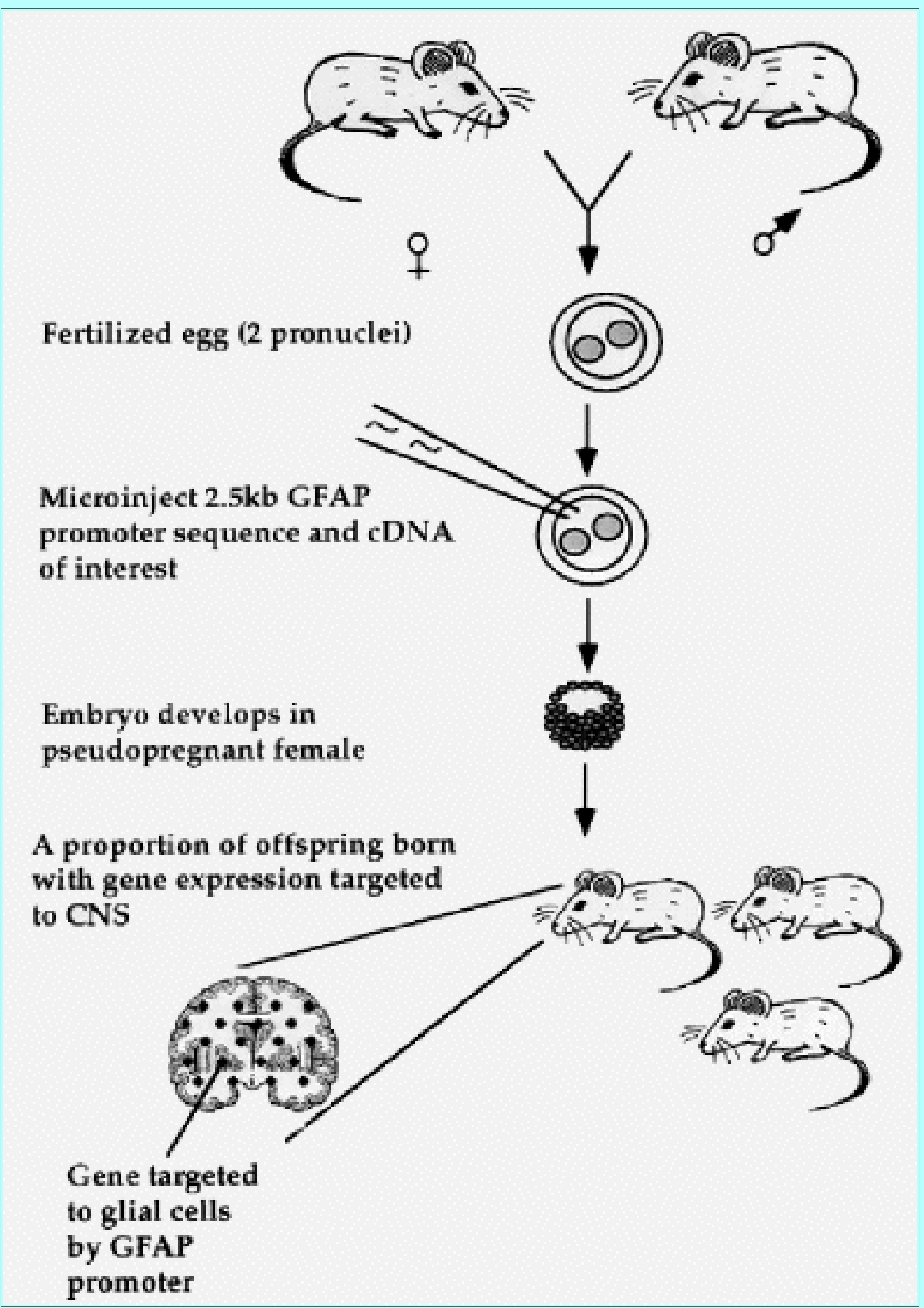

Fig. 5. Strategy for CNS gene targeting using the GFAP promoter sequence in transgenic mice. To obtain a gene expressed specifically in the brain, the gene of interest is placed in a DNA construct along with $2.5 \mathrm{~kb}$ of the GFAP promoter. The construct is then microinjected into fertilized mouse ova at the two- to four-cell stag. The developing mouse embryos are then implanted into pseudopregnant mice and allowed to develop to term. Once born, the transgenic mouse will express the gene of interest exclusively in glial cells of the CNS. In this way, the GFAP promoter has provided targeting specific sequences for the foreign gene to be expressed in the brain. Such targeting strategies using the GFAP promoter may ultimately prove useful in CNS gene therapy trials in humans. 
and is known as the standard form or GFAP-alpha. Alternate forms of GFAP mRNA have been described and have been termed GFAP-beta and GFAP-gamma.[10] The GFAP-beta mRNA was first described in the ethylnitrosourea-induced Schwann cell line, RT4-D6.[44] In the peripheral nervous system, GFAP-beta mRNA may be the predominant form of GFAP, whereas GFAP-alpha mRNA is the predominant form in the CNS.[10] The GFAP-gamma mRNA has been found in both CNS and non-CNS tissues including mouse bone marrow and spleen.[10] At this time, relatively little is known about the function and role of the alternate forms of GFAP mRNA in terms of protein formation. After the mRNA is translated into protein, however, GFAP undergoes posttranslational modifications, including blocking of the methionine at the $\mathrm{NH}_{2}$ terminus and phosphorylations. Of these, the phosphorylation of GFAP plays a pivotal role in GFAP structure and function.

Phosphorylation of a protein on serine, threonine, or tyrosine residues is a common posttranslational modification that allows for rapid and reversible alterations in protein conformation and function. Just as with other IFs and cytoskeletal proteins, GFAP does not exist in one static form. Rather, there is a continuous and dynamic shift from an assembled (filamentous) state to a disassembled (soluble) state.[48,49,79] In particular, phosphorylation of a number of IFs has been observed to occur during mitosis. Phosphorylation at this time point in the cell cycle may assist with the reorganization of GFAP that occurs during mitosis.[17,18,48,68] It is currently believed that phosphorylation in the aminoterminal region of GFAP is important for disassembly from a filamentous form into a soluble form (Fig. 6).[1,47,78,80] This disassembly of the filamentous protein likely facilitates equal separation of cytoplasmic components into two daughter cells during cytokinesis.

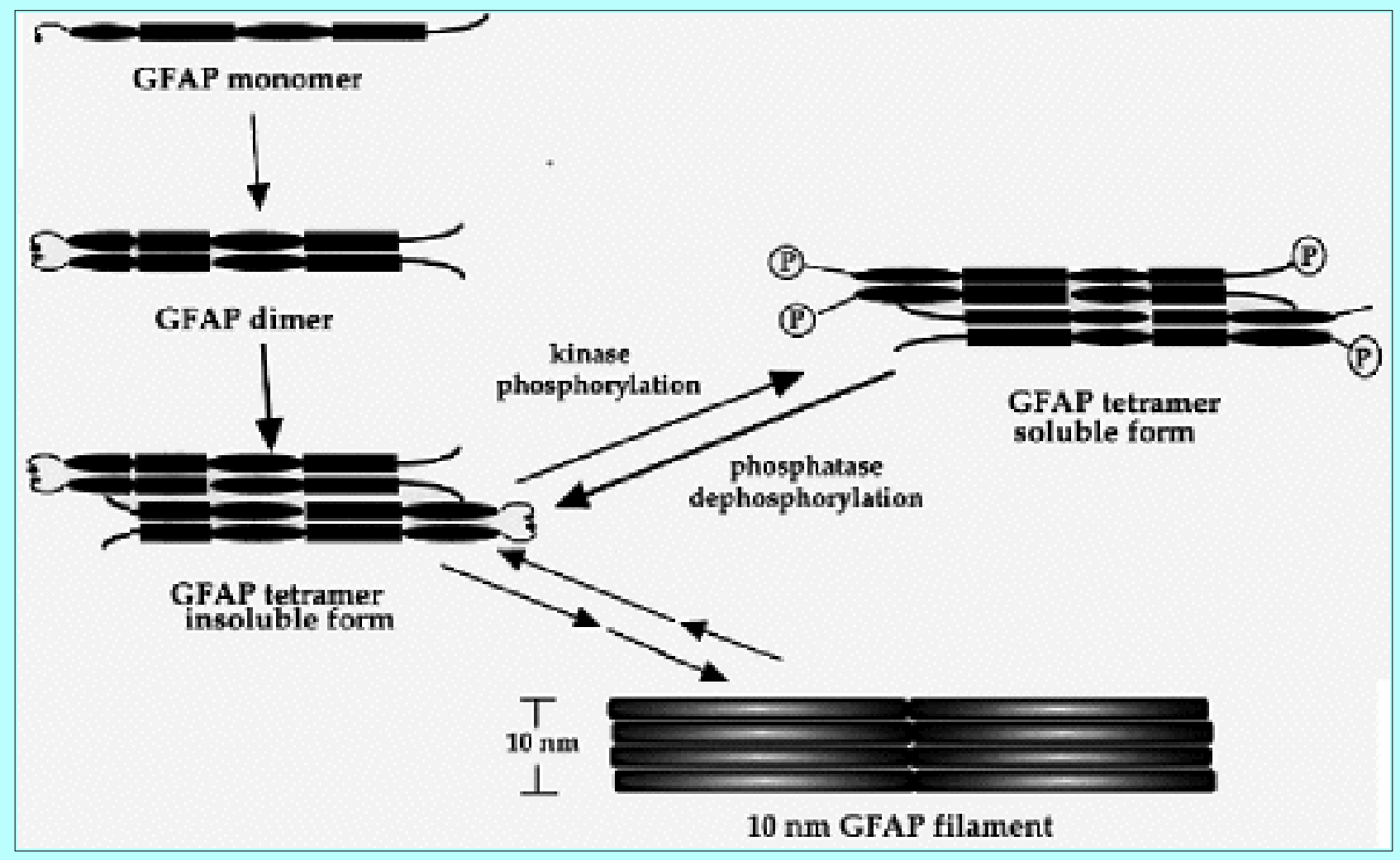

Fig. 6. Regulation of GFAP assembly and disassembly. Two GFAP molecules unite to form a GFAP dimer that takes the shape of an alpha-helical coil. Two GFAP dimers unite to form a tetramer of antiparallel protofilaments. Multiple tetramers assemble eventually to form the typical 10-nm IF bundles that are readily appreciated by electron microscopy. The 10-nm IF bundles are dynamic structures that shift between assembled and disassembled states. The 
phosphorylation of amino acid residues in the $\mathrm{NH}_{2}$-terminal region of GFAP by various kinases, including cdc2, leads to disassembly of GFAP filaments into a soluble form. Phosphatases can then act on the soluble form of GFAP to cleave phosphorylated residues, leading to the return to the insoluble form of GFAP as shown.

Proof that the $\mathrm{NH}_{2}$-terminal head region is indispensable for GFAP filament formation comes from a variety of different studies.[48,89] In one study, cleavage of the $\mathrm{NH}_{2}$ terminus of GFAP by thrombin digestion led to failure of GFAP assembly.[89] In other studies, serine and threonine residues in the $\mathrm{NH}_{2}$-terminal region of GFAP act as in vitro substrates for phosphorylation by a number of protein kinases including the cyclin-dependent kinase cdc2 (cdk1), cAMP-dependent kinase, $\mathrm{Ca}^{++}$-calmodulin-dependent kinase II, and protein kinase C.[48] The $\mathrm{NH}_{2}$-terminal phosphorylation of GFAP by these kinases promotes disassembly of already assembled glial filaments. At this time, it is not known precisely which phosphorylation sites on GFAP and which protein kinases are critical for GFAP disassembly. One report suggests that cdc 2 activity alone is not sufficient for mitotic disassembly in vitro, but that a $\mathrm{Ca}^{++}$-calmodulin-dependent kinase is the critical enzyme.[115] Although cdc2 phosphorylates GFAP on a single serine- 8 residue, $\mathrm{Ca}^{++}$-calmodulin-dependent kinase phosphorylates GFAP on serines 13,17 , and 34.[115]

It is conceivable that different protein kinases play roles in the reorganization of the astrocyte's cytoskeleton in response to a variety of stimuli.[122] In addition, the sequential activation of different protein kinases that phosphorylate different protein residues on GFAP may be critical to the process of glial filament disassembly in mitosis. When antibodies to different phosphorylated peptide regions of the $\mathrm{NH}_{2}$ terminus of GFAP were used to study GFAP expression, there was a difference in the expression of phosphorylated GFAP epitopes at the $\mathrm{G}_{2}$-metaphase transition and during cytokinesis.[81] These investigators have suggested that there may be two different mitotic GFAP kinases: cdc2, which acts first at the $\mathrm{G}_{2}-\mathrm{M}$ transition, followed by a yet-to-be-identified kinase, which acts during cytokinesis.

From these data it is apparent that phosphorylation of GFAP in the $\mathrm{NH}_{2}$-terminal domain is an important means of regulating GFAP assembly and disassembly. Glial fibrillary acidic protein is also phosphorylated at sites outside the head domain, but the significance of these phosphorylation sites is unknown. A better understanding of the role glial filaments play in the cytoskeleton of astrocytes will undoubtedly emerge soon from further studies that examine the sites and timing of GFAP phosphorylations.

\section{In Search of the Function of GFAP}

Glial Fibrillary Acidic Protein-Cytoskeleton Interactions. Despite the wealth of information now available concerning the IF family, we still know very little about the role that GFAP subserves in astrocytes and astrocytic tumors. Glial fibrillary acidic protein is thought to stabilize the astrocyte's cytoskeleton and to maintain astrocyte cell shape through interactions between GFAP filaments, the nuclear membrane, and the plasma membrane.[39] This statement is further supported by immunoelectron microscopy data that show abundant GFAP filaments at sites of contact between astrocytic processes and neurons, endothelial or leptomeningeal basal laminae.[93] Thus, GFAP forms a structural link between the nucleus and the plasma membrane.

The aforementioned physical interactions are likely mediated through a panoply of putative IF-associated 
proteins (IFAPs),[30,39,117,118] but the details of these interactions have yet to be fully characterized. Yang and associates[121] have recently described an essential cytoskeletal linker protein connecting neurofilaments to actin microfilaments. Mice deficient in this linker protein, termed BPAG1n, will undergo sensory neurodegeneration and will demonstrate a dystonia musculorum phenotype.[121] These authors have suggested that BPAG1n is vitally important for the neuron and the host and that severing the connections between the neurofilaments and actin microfilaments may adversely affect axonal transport mechanisms.[121] A different example of an IFAP that binds to GFAP to aid in cytoskeletal support is plectin. Plectin is a 300-kD protein first identified in the rat C6 astrocytoma cell line.[88] Part of plectin's primary sequence is related to desmoplakin and bullous pemphigoid antigen. Plectin has been shown to bind to several IFs and has been found in virtually all cell types. Plectin colocalizes with IFs at focal contact and actin stress fiber sites (Fig. 7).[105] Using immunoelectron microscopy, Bohn, et al.,[8] recently showed that vimentin IFs were structurally linked to actin microfilaments through thin (3-nm) connecting filaments similar in size to plectin. In cosedimentation experiments, however, plectin has not been shown to bind to F-actin directly.[105] Accordingly, it has been suggested that plectin may connect with actin filaments through actin-binding proteins.[105] Examples of well-characterized actin-binding proteins include actinin, talin, and vinculin. Interestingly, these actin-binding proteins are known to bind to the short cytoplasmic domains of the main mediators of cell-extracellular matrix (ECM) adhesion--the integrins (see following subsection).

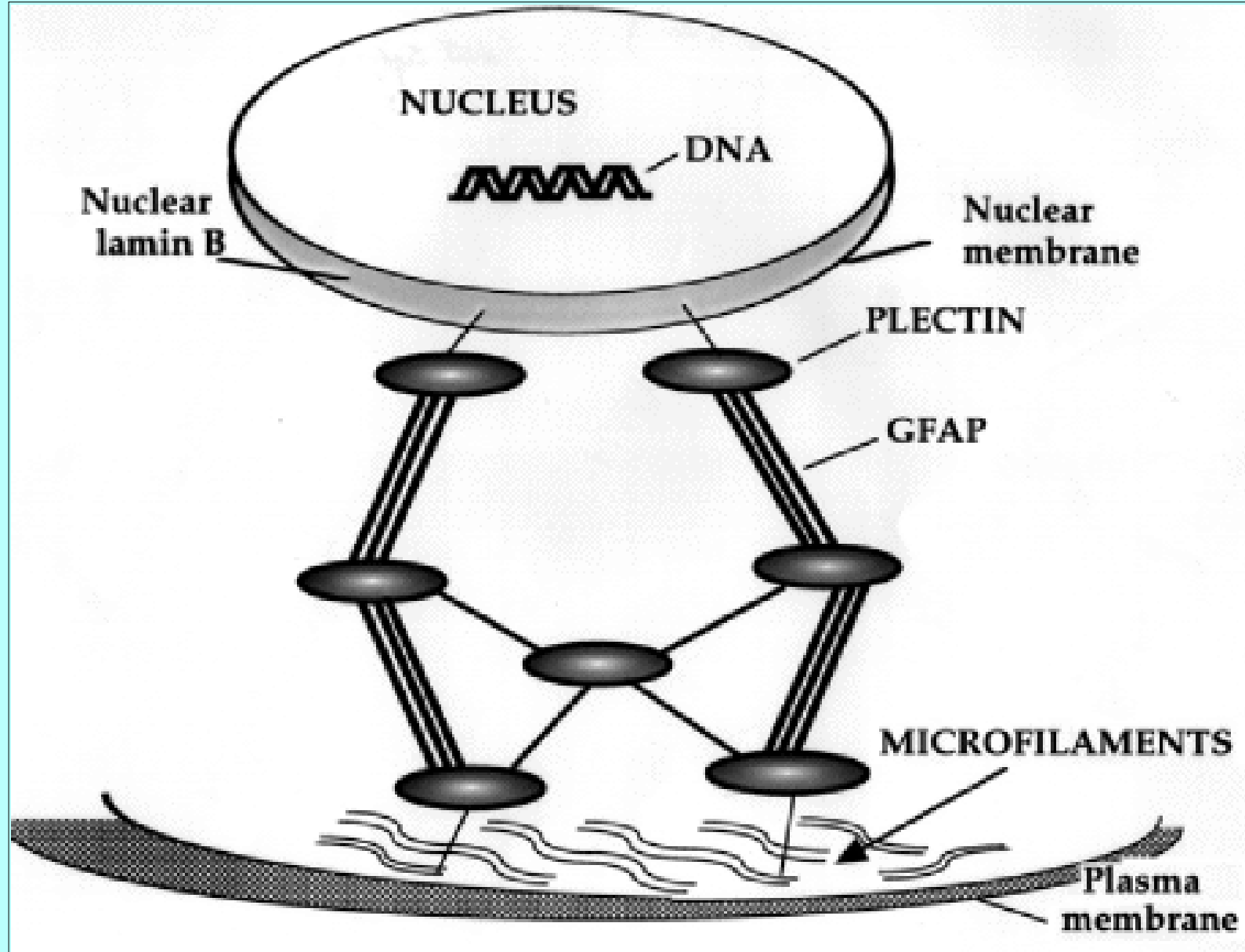

Fig. 7. Schematic model of interactions between GFAP and the IFAP known as plectin. Plectin binds to the highly conserved rod domain of GFAP and links GFAP to the nuclear membrane via interactions with nuclear lamin B and to the plasma membrane via possible interactions with the actin microfilamentous system. Plectin may also play an important role by linking to other cytoskeletal proteins such as the microtubules. 
Glial Fibrillary Acidic Protein: a Link to Glial Cell Adhesion? We previously observed that treatment of a GFAP-positive cell line, U-251MG, with antisense GFAP led to a marked reduction in cell adhesion.[100] The observations that IFs link to actin filaments by means of actin-binding proteins and that actin is linked to the cytoplasmic domains of integrins by virtue of these same actinbinding proteins suggest that actin and, to a lesser extent, GFAP are physically linked to the plasma membrane and will respond together to changes in cell morphology or the cellular microenvironment (Fig. 8). Integrins have been colocalized immunocytochemically with actin-containing microfilaments, and biochemical evidence has been obtained to indicate a direct binding of integrin cytoplasmic domains to certain cytoskeletal proteins, including talin and alpha-actinin, at sites of contact between the cells and their substrata. The integrins are a family of Type I transmembrane proteins composed of a large extracellular domain, a hydrophobic membrane spanning segment, and a short cytoplasmic domain.[46,94,105] Each integrin is composed of an alpha and a beta subunit. At present, there are at least 15 different alpha and nine beta subunits that can variously combine to form 21 receptors with distinct ligand specificities.[36] Integrins recognize specific peptide regions within ECM macromolecules, the best characterized of which is the arginine-glycine-aspartic sequence of fibronectin.[22-24,94]

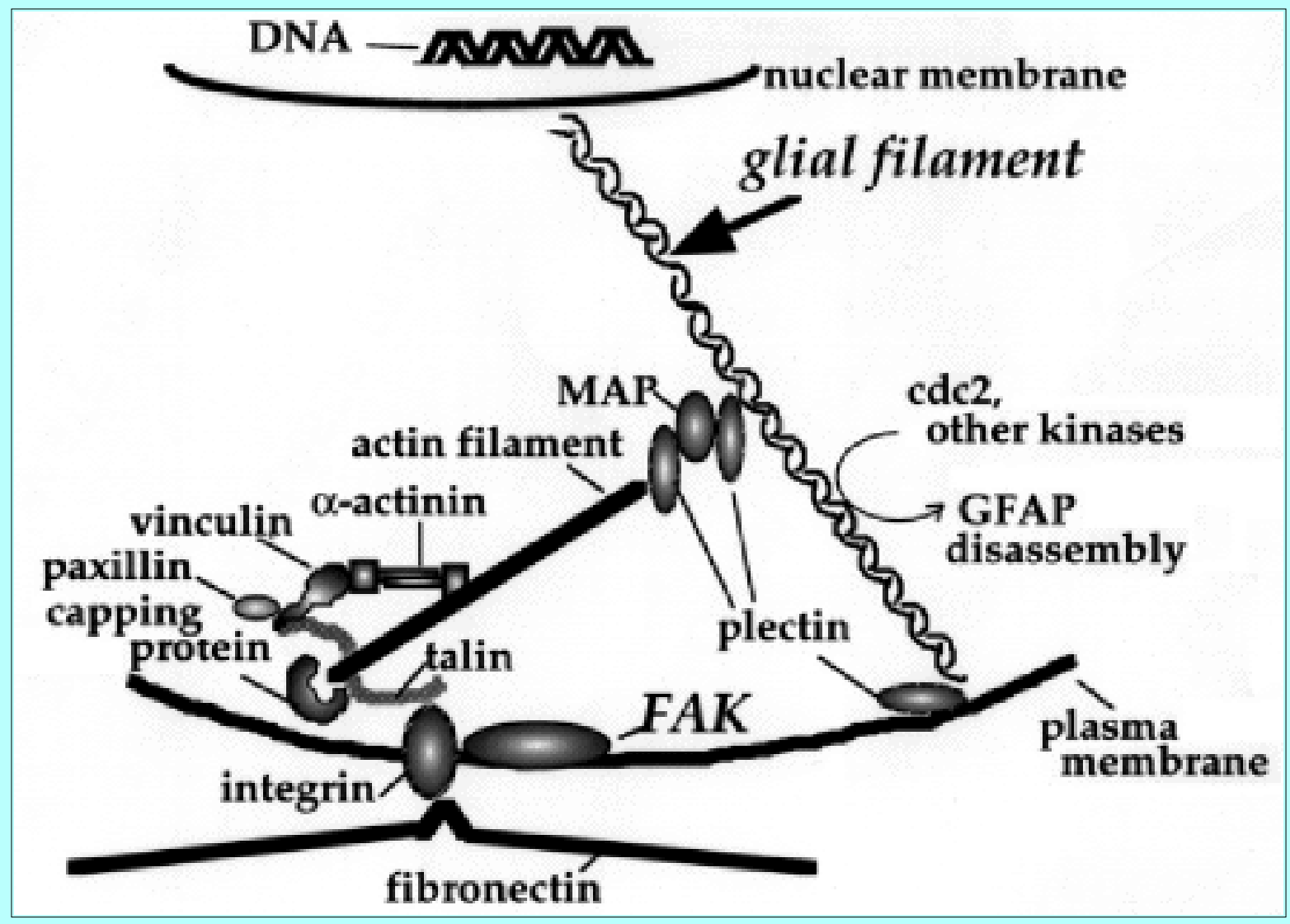

Fig. 8. Model of cytoskeleton-matrix interactions. In this model, glial filaments bridge the cytoplasmic space between nuclear and plasma membranes acting as a scaffold to which other molecules, such as plectin and actin microfilaments, may attach. The actin microfilaments are linked with a number of actin-binding proteins such as vinculin, paxillin, alpha-actinin, and talin. These actin-binding proteins are intimately associated with integrins at the level of the plasma membrane and at focal adhesion sites. At focal adhesions, the cytoskeleton is coupled to ECM substrates such as fibronectin through integrin binding. Binding of fibronectin to integrins leads to activation of FAK, which phosphorylates key cytoplasmic proteins capable of regulating regional cell morphology. cdc2 is one of several kinases capable of disassembling GFAP through phosphorylations of the head region of the 
molecule. Microtubule-associated binding protein (MAP) can bind to plectin.

A relationship between IFs and integrins has recently been elucidated via the molecular characterization of the hemidesmosome that contains keratin IFs linked to the alpha-6-beta-4 integrin through the bullous pemphigoid antigen.[16,36,110] It has been proposed that a reduction in integrin expression, as seen in many instances in transformed cells, leads to the dissociation of the ECM and the cytoskeleton, resulting in reduced adhesion and cytoskeletal disorganization.[22,87]

On binding to extracellular ligands, integrins cluster on the plane of the plasma membrane and promote the assembly of molecular complexes containing both cytoskeletal and signaling elements.[36,104] The effects that the ECM has on cellular growth and differentiation are likely mediated through various integrin signaling pathways (so-called "out/in" signaling). Although the integrin signaling pathways have not been completely characterized, many involve tyrosine kinase phosphorylation of neighboring protein species and cyclin-dependent kinases.[6,44,102,111] As one example, the study of ECM-induced aggregation of integrin receptors at focal adhesion sites led to the identification of a phosphorylated $125-\mathrm{kD}$ protein known as focal adhesion kinase (FAK). [44,102] This FAK has been shown to associate physically with two nonreceptor protein tyrosine kinases, pp60src and pp59fyn, via their Src homology 2 domains.[102] Interestingly, a number of recent studies have shown that induced changes in the cytoskeleton are also likely to perturb integrin-mediated signaling (so-called "in/out" signaling) (Fig. 8). $[37,91]$

Glial Fibrillary Acidic Protein and Signaling Pathways. In general, the progression of a cell through the cell cycle is ultimately controlled by a series of protein kinases whose activities are regulated by a group of proteins called cyclins. The cyclin-dependent protein kinases (cdks) phosphorylate key substrates that are required to facilitate the passage of the cell through each phase of the cell cycle. Two important regulatory points exist in the cell cycle: one at the $G_{2}-M$ interphase, and the other at the $G_{1}-S$ interphase. The protein kinase cdc2 interacts with cyclin $\mathrm{B}$ and cyclin A to regulate mitosis, and cdk2 interacts with a variety of cyclins (D1, D2, D3, E, and A) to regulate progression through the $\mathrm{G}_{1}$ phase and DNA synthesis.[107]

Intrinsic alterations of cell cycle genes and their expression have now been identified in a wide variety of human cancers.[71,75] As examples, overexpression and amplification of cyclin D1 has been demonstrated in human parathyroid adenoma, leukemia, lymphoma, esophageal carcinoma, and breast carcinoma.[13,44,51,52,84] Keyomarsi and Pardee and colleagues[54,55] demonstrated a deranged order of appearance of cyclins in synchronized breast carcinoma cell lines, with mitotic cyclins appearing prior to $\mathrm{G}_{1}$ cyclins. In addition, overexpression of cyclin $A$ has been shown to be associated with anchorage-independent cell growth, another hallmark of cancer cells in vitro.[42] There has been one previous report on the interaction of cyclin-dependent kinases and IFs.[108] In that paper, the activation of p34cdc 2 coordinated the mitotic reorganization of the vimentin IF network both by severing IF-IF connections mediated by IFAPs and by disassembling individual IFs into protofilaments. Because there are now reports that link IFs and integrins to cell cycle gene expression, $[42,111]$ future experiments in this field will undoubtedly clarify the role of GFAP in complex cellular responses such as process formation, cell adhesion, and cell motility.

Lessons Learned From Modulating GFAP Expression. Clues as to the function of glial filaments in normal human astrocytes and glial tumors have come from a number of studies in which GFAP expression has been modulated under experimental conditions. It is known that early in 
neuroembryogenesis, astrocytes may synthesize vimentin instead of GFAP as their primary IF.[7,109] The switch to GFAP predominance occurs prenatally in human astrocytes and is caused by factors that have yet to be elucidated. In vitro, cultured astrocytes modulate GFAP synthesis in response to cell density,[38] composition of growth media,[74] and hormones that stimulate cAMP production.[106]

Because GFAP is a cytoskeletal element that appears to play an important role in astrocytic differentiation and because it is the most specific marker for cells of astrocytic lineage, several groups have studied how the modulation of GFAP expression might affect astrocytoma growth and differentiation. In an earlier study, all-trans and 13-cis retinoic acid $\left(10^{-6} \mathrm{M}\right)$ were effective in decreasing the proliferation of GFAP-positive U-343MG-A astrocytoma cells and in increasing the amount of GFAP produced, as measured by enzyme-linked immunosorbent assay.[97] In another study, it was shown that ECM proteins derived from normal human leptomeningeal cells effectively stopped the proliferation of U-343MG-A astrocytoma cells and induced differentiation of these cells as calculated by a quantitative increase in cellular GFAP.[96,98] The results from these studies suggest that the upregulation of GFAP in GFAP-positive astrocytoma cells is associated with alterations in astrocytoma growth and morphology.

However, as the vast majority of human astrocytoma cell lines are GFAP negative and, consequently, similar to highly anaplastic astrocytomas in vivo, $[5,15,99,116]$ a study was performed in which GFAP expression was restored to GFAP-negative anaplastic astrocytoma cells. A GFAP-negative human astrocytoma cell line, SF-126, was stably transfected with an expression vector containing a cDNA for the entire coding sequence of the human GFAP gene.[101] Interestingly, GFAP-immunoreactive SF-126 astrocytoma clones were characterized by elongated cytoplasmic processes containing high concentrations of GFAP and demonstrated marked alterations in cellular morphology when compared to controls. In addition, the amount of GFAP mRNA expression and immunoreactivity among stably transfected astrocytoma clones correlated inversely with astrocytoma proliferation.[101]

Recently, studies have been performed in which the GFAP gene has been eliminated in transgenic "knockout" mice.[41,64,86] In two of these studies, GFAP-deficient mice appeared to develop and function normally, and in the areas of the brain subjected to detailed neuropathological study, no cytoarchitectural disturbances of the CNS of these mice have been found.[41,86] Although these authors did not examine the long-term effects of GFAP deficiency on the mouse brain, they postulated that $G F A P$-deficient mice may be more prone to advanced CNS aging than normal mice. This postulate has now been proved correct by Liedtke, et al.,[64] who showed that transgenic mice deficient in GFAP develop abnormal myelination in the spinal cord, optic nerve, and brain after 6 months. Ultrastructurally, the authors showed that astrocytic processes in GFAP-deficient mice were short and clublike, leading to reduced contacts between astrocytes and oligodendrocytes, and between astrocytes and myelin sheaths.[64] The altered myelination of the CNS in GFAP-deficient mice suggests an important link between astrocyte function and the maintenance of myelin. In addition, GFAP-deficient mice had poor white matter vascularization, which may have resulted from the loss of inductive influences of astrocytes on endothelial cells.[64] The implications from the study by Liedtke, et al., are profound because they suggest that for the CNS to retain structural and functional integrity with respect to CNS myelination, normal GFAP expression appears to be mandatory.

\section{CONCLUSIONS}

In summary, evidence is accumulating to suggest that GFAP may be involved as a collaborator in the 
complex cellular processes controlling astrocytoma cell morphology, adhesion, and proliferation. Glial fibrillary acidic protein may not represent a mere mechanical integrator of cellular space as has been previously thought. With several reports demonstrating that IFs may serve as "docking sites" for important kinases that recognize key cellular substrates, $[17,18,108,115,122]$ it is clear that GFAP helps to form a dynamic continuum with microfilaments, integrin receptors, and the ECM. Studies aimed at delineating how this continuum is affected by GFAP expression would be of great value in increasing our understanding of the role GFAP plays in modulating cell morphology and signaling pathways.

\section{References}

1. Almazan G, Afar DE, Bell JC: Phosphorylation and disruption of intermediate filament proteins in oligodendrocyte precursor cultures treated with calyculin A. J Neurosci Res 36:163-172, 1993

2. Balasingam V, Tejada-Berges $\mathrm{T}$, Wright $\mathrm{E}$, et al: Reactive astrogliosis in the neonatal mouse brain and its modulation by cytokines. J Neurosci 14:846-856, 1994

3. Balcarek JM, Cowan NJ: Structure of the mouse glial fibrillary acidic protein gene: implications for the evolution of the intermediate filament multigene family. Nucl Acids Res 13:5527-5543, 1985

4. Besnard F, Brenner M, Nakatani Y, et al: Multiple interacting sites regulate astrocyte-specific transcription of the human gene for glial fibrillary acidic protein. J Biol Chem 266:18877-18883, 1991

5. Bigner DD, Bigner SH, Pontén J, et al: Heterogeneity of genotypic and phenotypic characteristics of fifteen permanent cell lines derived from human gliomas. J Neuropathol Exp Neurol 40:201-229, 1981

6. Birge RB, Fajardo JE, Reichman C: Identification and characterization of a high-affinity interaction between v-Crk and tyrosine-phosphorylated paxillin in CT10-transformed fibroblasts. Mol Cell Biol 13:4648-4656, 1993

7. Bjorklund H, Eriksdotter-Nilsson M, Dahl D: Astrocytes in smears of CNS tissues as visualized by GFA and vimentin immunofluorescence. Med Biol 62:38-48, 1984

8. Bohn W, Röser K, Hohenberg H, et al: Cytoskeleton architecture of C6 rat glioma cell subclones differing in intermediate filament protein expression. J Struct Biol 111:48-58, 1993

9. Bongcam-Rudloff E, Nistér M, Betsholtz C, et al: Human glial fibrillary acidic protein:

complementary DNA cloning, chromosome localization, and messenger RNA expression in human glioma cell lines of various phenotypes. Cancer Res 51:1553-1560, 1991

10. Brenner M: Structure and transcriptional regulation of the GFAP gene. Brain Pathol 4:245-257, 1994

11. Brenner M, Kisseberth WC, Su Y, et al: GFAP promoter directs astrocyte-specific expression in transgenic mice. J Neurosci 14:1030-1037, 1994

12 Brenner M, Lampel K, Nakatani Y, et al: Characterization of human cDNA and genomic clones for glial fibrillary acidic protein. Mol Brain Res 7:277-286, 1990

13. Buckley MF, Sweeney KJE, Hamilton JA, et al: Expression and amplification of cyclin genes in human breast cancer. Oncogene 8:2127, 1993 
14. Campbell IL, Abraham CR, Masliah E, et al: Neurologic disease induced by transgenic mice by cerebral overexpression of interleukin 6. Proc Natl Acad Sci USA 90:10061-10065, 1993

15. Carlsson J, Nilsson K, Westermar KB, et al: Formation and growth of multicellular spheroids of human origin. Int J Cancer 31:523-533, 1983

16. Carter WG, Kaur P, Gil SG, et al: Distinct functions for integrins a3b1 in focal adhesions and a6b4/bullous pemphigoid antigen in a new stable anchoring contact (SAC) of keratinocytes: Relation to hemidesmosomes. J Cell Biol 111:3141-3154, 1990

17. Chou YH, Bischoff JR, Beach D, et al: Intermediate filament reorganization during mitosis is mediated by p34cdc2 phosphorylation of vimentin. Cell 62:1063-1071, 1990

18. Chou YH, Rosevear E, Goldman RD: Phosphorylation and disassembly of intermediate filaments in mitotic cells. Proc Natl Acad Sci USA 86:1885-1889, 1989

19. Coffin CM, Mukai K, Dehner LP: Glial differentiation in medulloblastomas. Histogenetic insight, glial reaction, or invasion of brain? Am J Surg Pathol 7:555-565, 1983

20. De Armond SJ, Eng LF, Rubinstein LJ: The application of glial fibrillary acidic protein (GFAP) protein immunohistochemistry in neuro-oncology. A progress report. Pathol Res Pract 168:374-394, 1980

21. Deck JHN, Eng LF, Bigbee J, et al: The role of glial fibrillary acidic protein in the diagnosis of central nervous system tumors. Acta Neuropathol 42:183-190, 1978

22. Dedhar S: Integrins and tumor invasion. Bioessays 12:583-590, 1990

23. Dedhar S, Gray V: Isolation of a novel integrin receptor mediating ARG-GLY-ASP-directed cell adhesion to fibronectin and type I collagen from human neuroblastoma cells. Association of a novel beta-1 related subunit with alpha ${ }_{\mathrm{v}}$. J Cell Biol 110:2185-2193, 1990

24. Dedhar S, Saulnier R: Alterations in integrin receptor expression in chemically transformed human cells: specific enhancement of laminin and collagen receptor complexes. J Cell Biol 110:481-489, 1990

25. Duffy PE: Glial fibrillary acidic protein and induced differentiation of glia in vitro. J Neurol Sci 53:443-460, 1982

26. Duffy PE, Huang YY, Rapport MM: The relationship of GFAP to the shape, motility and differentiation of human astrocytoma cells. Exp Cell Res 139:145-157, 1982

27. Eng LF, Ghirnikar RS: GFAP and astrogliosis. Brain Pathol 4:229-237, 1994

28. Eng LF, Rubinstein LJ: Contribution of immunohistochemistry to diagnostic problems of human cerebral tumors. J Histochem Cytochem 26:513-522, 1978

29. Eng LF, Vanderhaeghen JJ, Bignami A, et al: An acidic protein isolated from fibrous astrocytes. Brain Res 28:351-354, 1971

30. Errante LD, Wiche G, Shaw G: Distribution of plectin, an intermediate filament-associated protein, in the adult rat central nervous system. J Neurosci Res 37:515-528, 1994 
31. Fagan AM, Gage FH: Cholinergic sprouting in the hippocampus: a proposed role for IL-1. Exp Neurol 110:105-120, 1990

32. Fallon JH, Annis CM, Gentry LE, et al: Localization of cells containing transforming growth factor-alpha precursor immunoreactivity in the basal ganglia of the adult rat brain. Growth Factors 2:241-250, 1990

33. Finch CE, Laping NJH, Morgan TE, et al: TGF-beta1 is an organizer of responses to neurodegeneration. J Cell Biochem 53:314-322, 1993

34. Fuchs E, Weber K: Intermediate filaments: structure, dynamics, function, and disease. Ann Rev Biochem 63:345-382, 1994

35. Galou M, Pournin S, Ensergueix D, et al: Normal and pathological expression of GFAP promoter elements in transgenic mice. Glia 12:281-293, 1994

36. Giancotti FG, Mainiero F: Integrin-mediated adhesion and signaling in tumorigenesis. Biochem Biophys Acta 1198:47-64, 1994

37. Glück U, Kwiatkowski DJ, Ben-Ze'ev A: Suppression of tumorigenicity in simian virus 40-transformed 3 T3 cells transfected with alpha-actinin cDNA. Proc Natl Acad Sci USA 90:383-387, 1993

38. Goldman JE, Chiu FC: Growth kinetics, cell shape, and the cytoskeleton of primary astrocytic cultures. J Neurochem 42:175-184, 1984

39. Goldman RD, Zackroff RV, Steinert PM: Intermediate filaments: overview, in Goldman RD, Steinert PM (eds): Cellular and Molecular Biology of Intermediate Filaments. New York: Plenum, 1990, pp $3-20$

40. Gómez-Pinilla F, Lee JWK, Cotman CW: Basic FGF in adult rat brain: cellular distribution and response to entorhinal lesion and fimbria fornix transection. J Neurosci 12:345-355, 1992

41. Gomi H, Yokoyama T, Fujimoto K, et al: Mice devoid of the glial fibrillary acidic protein develop normally and are susceptible to scrapie prions. Neuron 14:29-41, 1995

42. Guadagno TM, Ohtsubo M, Roberts JM, et al: A link between cyclin A expression and adhesion-dependent cell cycle progression. Science 262:1572-1575, 1993

43. Hagiwara N, Imada S, Sueoka N: Cell-type specific segregation of transcriptional expression of glial genes in the rat peripheral neurotumor RT4 cell lines. J Neurosci Res 36:646-656, 1993

44. Hanks SK, Calalb MB, Harper MC, et al: Focal adhesion protein-tyrosine kinase phosphorylated in response to cell attachment to fibronectin. Proc Natl Acad Sci USA 89:8487-8491, 1992

45. Hatten ME, Mason CA: Neuron-astroglia interactions in vitro and in vivo. Trends Neurosci 9:168-174, 1986

46. Humphries MJ, Mould AP, Tuckwell DS: Dynamic aspects of adhesion receptor function--integrins both twist and shout. Bioessays 15:391-397, 1993 
47. Inagaki M, Gonda Y, Nishizawa K, et al: Phosphorylation sites linked to glial filament disassembly in vitro locate in a non-alpha-helical head domain. J Biol Chem 265:4722-4729, 1990

48. Inagaki M, Nakamura Y, Takeda M, et al: Glial fibrillary acidic protein: dynamic property and regulation by phosphorylation. Brain Pathol 4:239-243, 1994

49. Inagaki M, Nishi Y, Nishizawa K, et al: Site-specific phosphorylation induces disassembly of vimentin filaments in vitro. Nature 328:649-652, 1987

50 Jacques CM, Kujas M, Poreau A: GFA and S 100 protein levels as an index for malignancy in human gliomas and neurinomas. J Natl Cancer Inst 62:479-483, 1981

51. Jiang W, Kahn SM, Tomita N, et al: Amplification and expression of the human cyclin D gene in esophageal cancer. Cancer Res 52:2980-2984, 1992

52. Jiang W, Zhang YJ, Kahn SM, et al: Altered expression of the cyclin D1 and retinoblastoma genes in human esophageal cancer. Proc Natl Acad Sci USA 90:9026-9030, 1993

53. Junier MP, Ma YJ, Costa ME, et al: Transforming growth factor alpha contributes to the mechanisms by which hypothalamic injury induces precocious puberty. Proc Natl Acad Sci USA 88:9743-9747, 1991

54. Keyomarsi K, Pardee AB: Redundant cyclin overexpression and gene amplification in breast cancer cells. Proc Natl Acad Sci USA 90:1112-1116, 1993

55. Keyomarsi K, Sandoval L, Band V, et al: Synchronization of tumor and normal cells from G1 to multiple cell cycles by lovastatin. Cancer Res 51:3602-3609, 1991

56. Kleihues P, Kiessling M, Janzer RC: Morphological markers in neuro-oncology. Curr Top Pathol 77:307-338, 1987

57. Lalley PA, Davisson MT, Graves JAM, et al: Report of the committee on comparative mapping. Cytogenet Cell Genet 51:503-532, 1989

58. Laping NJ, Teter B, Nichols NR, et al: Glial fibrillary acidic protein: regulation by hormones, cytokines, and growth factors. Brain Pathol 1:259-275, 1994

59. Laws ER Jr, Taylor WF, Clifton MB, et al: Neurosurgical management of low-grade astrocytomas of the cerebral hemispheres. J Neurosurg 61:665-673, 1984

60. Lazarides E: Intermediate filaments: a chemically heterogeneous, developmentally regulated class of proteins. Annu Rev Biochem 51:219-250, 1982

61. Lendahl U, Zimmerman LB, McKay RDG: CNS stem cells express a new class of intermediate filament protein. Cell 60:585-595, 1990

62. Levitt P, Rakic P: Immunoperoxidase localization of glial fibrillary acidic proteinP in radial glial cells and astrocytes of the developing rhesus monkey brain. J Comp Neurol 193:815-840, 1980

63. Lewis SA, Balcarek JM, Krek V, et al: Sequence of a cDNA clone encoding mouse glial fibrillary acidic protein: structural conservation of intermediate filaments. Proc Natl Acad Sci USA 81:2743-2746, 1984 
64. Liedtke W, Edelmann W, Bieri PL, et al: GFAP is necessary for the integrity of CNS white matter architecture and long-term maintenance of myelination. Neuron 17:607-615, 1996

65. Maraziotis T, Perentes E, Karamitopoulou E, et al: Neuron-associated class III beta-tubulin isotype, retinal S-antigen, synaptophysin, and glial fibrillary acidic protein in human medulloblastomas: a clinicopathological analysis of 36 cases. Acta Neuropathol 84:355-363, 1992

66. Masood K, Besnard F, Su Y, et al: Analysis of a segment of the human glial fibrillary acidic protein gene that directs astrocyte-specific transcription. J Neurochem 61:160-166, 1993

67. Mathewson AJ, Berry M: Observations on the astrocyte response to a cerebral stab wound in adult rats. Brain Res 327:61-69, 1985

68. Matsuoka Y, Nishizawa K, Yano T, et al: Two different protein kinases act on a different time schedule as glial filament kinases during mitosis. EMBO J 11:2895-2902, 1992

69. McLendon RE, Bigner DD: Immunohistochemistry of the glial fibrillary acidic protein: basic and applied considerations. Brain Pathol 4:221-228, 1994

70. McLendon RE, Burger PC, Pegram CN, et al: The immunohistochemical application of three anti-GFAP monoclonal antibodies to formalin-fixed, paraffin-embedded, normal and neoplastic brain tissues. J Neuropathol Exp Neurol 45:692-703, 1986

71. Milam SB, Magnuson VL, Steffensen B, et al: IL-1 beta and prostaglandins regulate integrin mRNA expression. J Cell Physiol 149:173-183, 1991

72. Miyake T, Hattori T, Fukuda M, et al: Quantitative studies on proliferative changes of reactive astrocytes in mouse cerebral cortex. Brain Res 451:133-138, 1988

73. Molenaar WM, Jansson DS, Gould VE, et al: Molecular markers of primitive neuroectodermal tumors and other pediatric central nervous system tumors. Monoclonal antibodies to neuronal and glial antigens distinguish subsets of primitive neuroectodermal tumors. Lab Invest 61:635-643, 1989

74. Morrison RS, De Vellis J, Lee Y, et al: Hormones and growth factors induce the synthesis of glial fibrillary acidic protein in rat brain astrocytes. J Neurosci Res 14:167-176, 1985

75. Motokura T, Arnold A: Cyclins and oncogenesis. Biochem Biophys Acta 1155:63-78, 1993

76. Mucke L, Oldstone MBA, Morris JC, et al: Rapid activation of astrocyte-specific expression of GFAP-lacZ transgene by focal injury. New Biologist 3:465-474, 1991

77. Nakagawa Y, Perentes E, Rubinstein LJ: Immunohistochemical characterization of oligodendrogliomas: an analysis of multiple markers. Acta Neuropathol 72:15-22, 1986

78. Nakamura Y, Takeda M, Aimoto S, et al: Assembly regulatory domain of glial fibrillary acidic protein. A single phosphorylation diminishes its assembly-accelerating property. J Biol Chem 267:23269-23274, 1992

79. Nakamura Y, Takeda M, Angelides KJ, et al: Assembly, disassembly, and exchange of glial fibrillary acidic protein. Glia 4:101-110, 1991

80. Nakatani Y, Horikoshi M, Brenner M, et al: A downstream initiation element required for efficient 
TATA box binding and in vitro function of TFIID. Nature 348:86-88, 1990 (Letter)

81. Nishizawa K, Yano T, Shibata M, et al: Specific localization of phosphointermediate filament protein in the constricted area of dividing cells. J Biol Chem 266:3074-3079, 1991

82. Oh YJ, Markelonis GJ, Oh TH: Effects of interleukin-1 beta and tumor necrosis factor-alpha on the expression of glial fibrillary acidic protein and transferrin in cultured astrocytes. Glia 8:77-86, 1993

83. Osborn M, Weber K: Intermediate filament proteins: a multigene family distinguishing major cell lineages. Trends Biochem Sci 11:469-471, 1986

84. Palmero I, Holder A, Sinclair AJ: Cyclins D1 and D2 are differentially expressed in human B-lymphoid cell lines. Oncogene 8:1049-1054, 1993

85. Pegram CN, Eng LF, Wikstrand CJ, et al: Monoclonal antibodies reactive with epitopes restricted to glial fibrillary acidic proteins of several species. Neurochem Pathol 3:119-138, 1985

86. Pekny M, Levéen P, Pekna M, et al: Mice lacking glial fibrillary acidic protein display astrocytes devoid of intermediate filaments but develop and reproduce normally. EMBO J 14:1590-1598, 1995

87. Plantefaber LC, Hynes RO: Changes in integrin receptors on oncogenically transformed cells. Cell 56:281-290, 1989

88. Pytela R, Wiche G: High molecular weight polypeptides $(270,000-34,000)$ from cultured cells are related to hog brain microtubule-associated proteins but copurify with intermediate filaments. Proc Natl Acad Sci USA 77:4808-4812, 1980

89. Quinlan RA, Moir RD, Stewart M: Expression in Escherichia coli fragments of glial fibrillary acidic protein: characterization, assembly properties and paracrystal formation. J Cell Sci 93:71-83, 1989

90. Reeves SA, Helman LJ, Allison A, et al: Molecular cloning and primary structure of human glial fibrillary acidic protein. Proc Natl Acad Sci USA 86:5178-5182, 1989

91. Rodriguez Fernandez JLR, Geiger B, Salomon D, et al: Suppression of vinculin expression by antisense transfection confers changes in cell morphology, motility, and anchorage-dependent growth of 3 T3 cells. J Cell Biol 122:1285-1294, 1993

92. Rorke LB, Molenaar WM, Trojanowski JQ: New trends in clinical research, in Packer RJ, Bleyer WA, Pochedly C (eds): Pediatric Neuro-Oncology. Monographs in Clinical Pediatrics, Vol 3. New York: Harwood Academic, 1992, pp 8-32

93. Rubinstein LJ: Tumors of the Central Nervous System. Atlas of Tumor Pathology, Series 2, Fascicle 6. Washington, DC: Armed Forces Institute of Pathology, 1972

94. Ruoslahti E: Integrins. J Clin Invest 87:1-5, 1991

95. Russell DS, Rubinstein LJ: Pathology of Tumours of the Nervous System, ed 5. Baltimore: Williams \& Wilkins, 1989, pp 30-31

96. Rutka JT, Apodaca G, Stern R, et al: The extracellular matrix of the central and peripheral nervous systems: structure and function. J Neurosurg 69:155-170, 1988 
97. Rutka JT, De Armond SJ, Giblin JR, et al: Effects of retinoids on the proliferation, morphology, and expression of glial fibrillary acidic protein of an anaplastic astrocytoma cell line. Int $\mathbf{J}$ Cancer 42:419-427, 1988

98. Rutka JT, Giblin JR, Apodaca G, et al: Inhibition of growth and induction of differentiation in a malignant human glioma cell line by normal leptomeningeal extracellular matrix proteins. Cancer Res 47:3515-3522, 1987

99. Rutka JT, Giblin JR, Dougherty DY, et al: Establishment and characterization of five cell lines derived from human malignant gliomas. Acta Neuropathol 75:92-103, 1987

100. Rutka JT, Hubbard SL, Fukuyama K, et al: Effects of antisense glial fibrillary acidic protein complementary DNA on the growth, invasion, and adhesion of human astrocytoma cells. Cancer Res 54:3267-3272, 1994

101. Rutka JT, Smith SL: Transfection of human astrocytoma cells with glial fibrillary acidic protein complementary DNA: analysis of expression, proliferation, and tumorigenicity. Cancer Res 53:3624-3641, 1993

102. Schaller MD, Borgman CA, Cobb BS, et al: pp125FAK, a structurally distinctive protein-tyrosine kinase associated with focal adhesions. Proc Natl Acad Sci USA 89:5192-5196, 1992

103. Schuster H, Jellinger K, Gund A, et al: Extracranial metastases of anaplastic cerebral gliomas. Acta Neurochir 35:247-259, 1976

104. Schwartz MA: Signaling by integrins: implications for tumorigenesis. Cancer Res 53:1503-1506, 1993

105. Seifert GJ, Lawson D, Wiche G: Immunolocalization of the intermediate filament-associated protein plectin at focal contacts and actin stress fibers. Eur J Cell Biol 59:138-147, 1992

106. Shafit-Zagardo B, Kume-Iwaki A, Goldman JE: Astrocytes regulate GFAP mRNA levels by cyclic AMP- and protein kinase C-dependent mechanisms. Glia 1:346-354, 1988

107. Sherr CJ: Mammalian $G_{1}$ cyclins. Cell 73:1059-1065, 1993

108. Skalli O, Chou YH, Goldman RD: Cell cycle-depndent changes in the organization of an intermediate filament-associated protein: correlation with phosphorylation by p34 ${ }^{\mathrm{cdc}}$. Proc Natl Acad Sci USA 89:11959-11963, 1992

109. Steinert PM, Jones JCR, Goldman RD: Intermediate filaments. J Cell Biol 99 (Suppl):22s-27s, 1984

110. Stepp MA, Spurr-Michaud S, Tisdale A, et al: alpha-6-beta-4 integrin heterodimer is a component of hemidesmosomes. Proc Natl Acad Sci USA 87:8970-8974, 1990

111. Symington BE: Fibronectin receptor modulates cyclin-dependent kinase activity. J Biol Chem 267:25744-25747, 1992

112. Takamiya Y, Kohsaka S, Otani M, et al: Immunohistochemical studies on the proliferation of reactive astrocytes and the expression of cytoskeletal proteins following brain injury in rats. Dev Brain 
Res 38:201-210, 1988

113. Takamiya Y, Kohsaka S, Toya S, et al: Possible association of platelet derived growth factor (PDGF) with the appearance of reactive astrocytes following brain injury in situ. Brain Res 383:305-309, 1986

114. Toggas SM, Masliah E, Rockenstein EM, et al: Central nervous system damage produced by expression of the HIV-1 coat protein gp120 in transgenic mice. Nature 367:188-193, 1994

115. Tsujimura K, Tanaka J, Ando S, et al: Identification of phosphorylation sites on glial fibrillary acidic protein for cdc 2 kinase and $\mathrm{Ca}^{2+}$-calmodulin-dependent protein kinase II. J Biochem 116:426-434, 1994

116. Westphal M, Haensel M, Mueller D, et al: Biological and karyotypic characterization of a new cell line derived from a human gliosarcoma. Cancer Res 48:731-740, 1988

117. Wiche G: Plectin: general overview and appraisal of its potential role as a subunit protein of the cytomatrix. Crit Rev Biochem Mol Biol 24:41-67, 1989

118. Wiche G, Gromov D, Donovan A, et al: Expression of plectin mutant cDNA in cultured cells indicates a role of $\mathrm{COOH}$-terminal domain in intermediate filament association. J Cell Biol 121:607-619, 1993

119. Woodroofe MN, Sarna GS, Wadhwa M, et al: Detection of interleukin-1 and interleukin-6 in adult rat brain, following mechanical injury by in vivo microdialysis: evidence of a role for microglia in cytokine production. J Neuroimmunol 33:227-236, 1991

120. Yan HQ, Banos MA, Herregodts P, et al: Expression of interleukin (IL)-1 beta, IL-6 and their respective receptors in the normal rat brain and after injury. Eur J Immunol 22:2963-2971, 1992

121. Yang Y, Dowling J, Yu QC, et al: An essential cytoskeletal linker protein connecting actin microfilaments to intermediate filaments. Cell 86:655-665, 1996

122. Yano S, Fukunaga K, Ushio Y, et al: Activation of $\mathrm{Ca}^{2+} /$ calmodulin-dependent protein kinase II and phosphorylation of intermediate filament proteins by stimulation of glutamate receptors in cultured rat cortical astrocytes. J Biol Chem 269:5428-5439, 1994

Manuscript received September 3, 1996.

Accepted in final form May 5, 1997.

Address reprint requests to: James T. Rutka, M.D., Ph.D., The Division of Neurosurgery, Suite 1502, The Hospital for Sick Children, 555 University Avenue, Toronto, Ontario, Canada M5G 1X8. E-mail: rutka@sickkids.on.ca.

This work was supported in part by grants from the National Cancer Institute, the Medical Research Council of Canada, The Lunenfeld Foundation, The Research Institute, The Hospital for Sick Children, and Brainchild. Dr. Dirks was supported by a Research Fellowship from The National Cancer Institute, Canadian Cancer Society, and the Medical Research Council of Canada. 